\title{
A Combined Experimental and Theoretical Investigation on Pyrazolone Derivative as Corrosion Inhibitor for Mild Steel in 0.5 M Sulphuric Acid Media
}

\author{
D. Nalini, ${ }^{*}$ K.S. Kohilah, Sowmya Ramkumar \\ Department of Chemistry, PSGR Krishnammal College for Women Coimbatore - 641 004,
} Tamil Nadu, India

Received 5 December 2013; accepted 23 April 2014

\begin{abstract}
The inhibition action of the Pyrazolone Derivative (PYR) on the corrosion of mild steel in $0.5 \mathrm{M}$ sulphuric acid was investigated by weight loss, polarization, impedance and SEM. Results obtained revealed that PYR performed excellently as corrosion inhibitor with efficiency of $91 \%$ at $11 \mathrm{ppm}$ at $298 \mathrm{~K}$. Its adsorption on mild steel obeys Langmuir and Temkin isotherm. Polarization curves indicate that PYR behaves as mixed type. The value of $\Delta \mathrm{G}_{\text {ads }}^{\circ}$ indicates the spontaneous physisorption of PYR. The SEM results confirm the presence of a protective surface layer over the mild steel surface. The reactivity of the compound was analysed through theoretical calculation.
\end{abstract}

Keywords: acid corrosion, mild steel, pyrazolone, theoretical studies, sulphuric acid medium.

\section{Nomenclature}

Substituted pyrazolone derivative: PYR; 0.5 molar sulphuric acid: $0.5 \mathrm{M} \mathrm{H}_{2} \mathrm{SO}_{4}$; mild steel: MS; parts per million: ppm; inhibitor concentration: Conc (ppm by weight); temperature: $\mathrm{T}(\mathrm{K})$; degree of surface coverage: $\theta$; inhibitor efficiency: $\eta(\%)$; corrosion rate: $\mathrm{R}\left(\mathrm{gm}^{-2} \mathrm{~h}^{-1}\right)$; mills per year: mpy; activation energy: $\mathrm{E}_{\mathrm{a}}$ $(\mathrm{kJ} / \mathrm{mol})$; free energy of adsorption: $\Delta \mathrm{G}^{\circ}$ ads $(\mathrm{kJ} / \mathrm{mol})$; heat of adsorption: $\Delta \mathrm{H}^{\circ}$ $(\mathrm{kJ} / \mathrm{mol})$; entropy of adsorption: $\Delta \mathrm{S}^{\circ}(\mathrm{Jmol} / \mathrm{K})$; correlation coefficient: $\mathrm{R}^{2}$; Electrochemical Impedance Spectroscopy: EIS; charge transfer resistance: $R_{c t}$ (ohms); double layer capacitance: $\mathrm{C}_{\mathrm{dl}}$ (farads); corrosion potential: $\mathrm{E}_{\text {corr }}(\mathrm{mV}$ vs. SCE); corrosion current: $I_{\text {corr }}$ (in $\mu \mathrm{A} / \mathrm{cm}^{2}$ ); micro amperes per centimetre square: $\mu \mathrm{A} / \mathrm{cm}^{2}$; cathodic Tafel slope: $b_{c}$ (in $\left.\mathrm{mV} / \mathrm{dec}\right)$; anodic Tafel slope: $b_{a}(\mathrm{mV} / \mathrm{dec})$;

\footnotetext{
*Corresponding author. E-mail address: nalinichemistry@gmail.com
} 
decades: dec; Scanning Electron Microscopy: SEM ; milli volt: $\mathrm{mV}$; Parametric Method 6: PM6; Parametric Method 7: PM7; electron volt: eV; Ionisation Potential: IP (V); Energy of the Highest Occupied Molecular Orbital: $\mathrm{E}_{\mathrm{HOMO}}$ $(\mathrm{eV})$; Energy of the Lowest Unoccupied Molecular Orbital: $\mathrm{E}_{\mathrm{LuMO}}(\mathrm{eV})$; Energy gap between LUMO and HOMO: $\triangle \mathrm{E}(\mathrm{eV})$.

\section{Introduction}

Acid solutions are widely used for industrial cleaning, oil well acidification and pickling. The corrosion of mild steel in such an environment is a fundamental academic and industrial concern which has received a considerable amount of attention in recent years due to its vast applications in all fields of engineering. To reduce these corrosion problems, a variety of inhibitive procedures have been tried so far. Among them, well known and highly studied inhibitors include organic compounds containing nitrogen, sulphate and oxygen atoms [1-10]. A perusal of the literature on acid corrosion inhibitors reveals that these organic molecules can adsorb on the metal surface through the hetero atom (such as nitrogen, oxygen, sulphur and phosphorous), multiple bonds or aromatic rings and block the active sites thereby decreasing the corrosion rate [11 - 15]. It has been observed that the adsorption of the organic molecule depends mainly on the electronic and structural properties of the inhibitor molecule such as functional group, steric factor, aromaticity, electron density on the donor atoms and $\pi$ orbital character of the donating electron [16-18]. Quantum chemical methods play a significant role in solving this problem [19-22]. R.S. Abdel Hameed et al. [23], investigated 5-chloro-1-phenyl-3-methyl pyrazolo-4-methinethiosemicarbazone as corrosion inhibitors for carbon steel in $\mathrm{HCl}$ by chemical and electrochemical method. L. Herrag et al. [24] evaluated the effect of $1-\{$ [benzyl(2-cyano-ethyl)-amino]-methyl $\}-5$-methyl-1H-pyrazole-3- carboxylic acid methyl ester and 1-\{[benzyl-(2-cyano-ethyl)-amino]-methyl $\}-5$ - methyl-1Hpyrazole-3-carboxylic acid ethyl ester as corrosion inhibitors for steel in molar hydrochloric acid using weight loss measurements and electrochemical polarisation technique.

With these ideas, in the present work electrochemical and non-electrochemical techniques were used to investigate the inhibitive action of the synthesised substituted pyrazolone derivative (PYR) on the corrosion on MS, with respect to inhibitor concentration and temperature, in $0.5 \mathrm{M}$ sulphuric acid medium. The thermodynamic parameters for both dissolution and adsorption processes were calculated and discussed. Quantum chemical calculation was used to explain the experimental results obtained in this study and also to give a further insight to the inhibitive action of PYR on the MS surface.

\section{Materials and methods}

\section{Materials used}

Synthesis of inhibitors

Substituted pyrazolone derivative (PYR) has been chosen as inhibitor for the present investigation. The synthesis of PYR involves two stages. 
Stage I: preparation of aliphatic thiosemicarbazide (scheme 1)

About 0.1 mole of the 1, 4 - diamine butane was dissolved in $50 \mathrm{~mL}$ of $95 \%$ ethanol, and $20 \mathrm{~mL}$ of $\mathrm{NH}_{4} \mathrm{OH}$ were added to it. After cooling the reaction mixture below $30{ }^{\circ} \mathrm{C}, 8 \mathrm{~mL}$ of $\mathrm{CS}_{2}$ were added slowly for 15 minutes with constant shaking. After complete addition of $\mathrm{CS}_{2}$, the solution was allowed to stand for an hour. Then about $20 \mathrm{~mL}$ of $50 \%$ solution of hydrazine hydrate were added. The mixture was warmed gently and kept overnight. The product obtained was washed, filtered and recrystallized from ethanol.

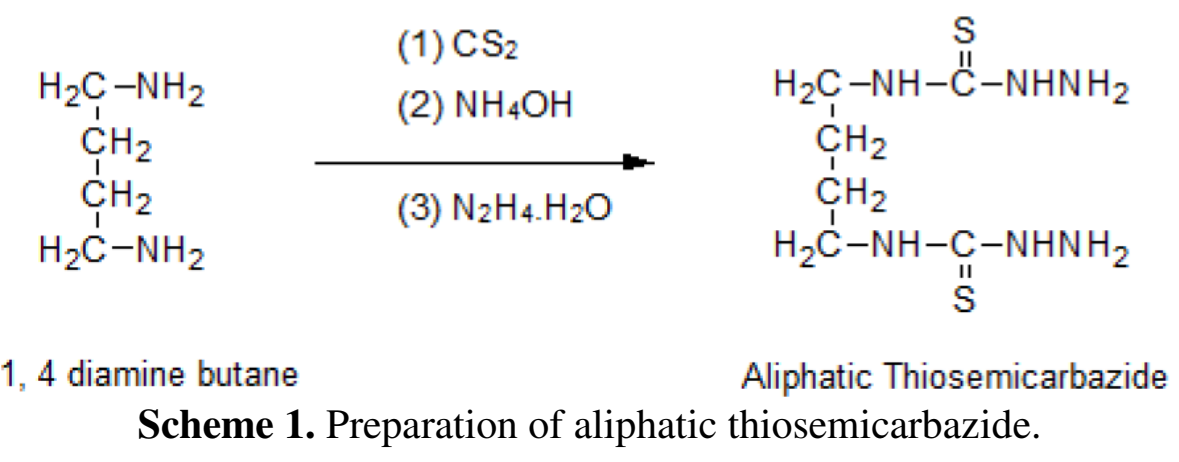

Stage II: preparation of substituted pyrazolone derivative (scheme 2)

0.1 mole of the aliphatic thiosemicarbazide was heated with 0.1 mole of ethyl acetoacetate for 4 - 6 hours. The product obtained was isolated from ether and recrystallized from ethanol.
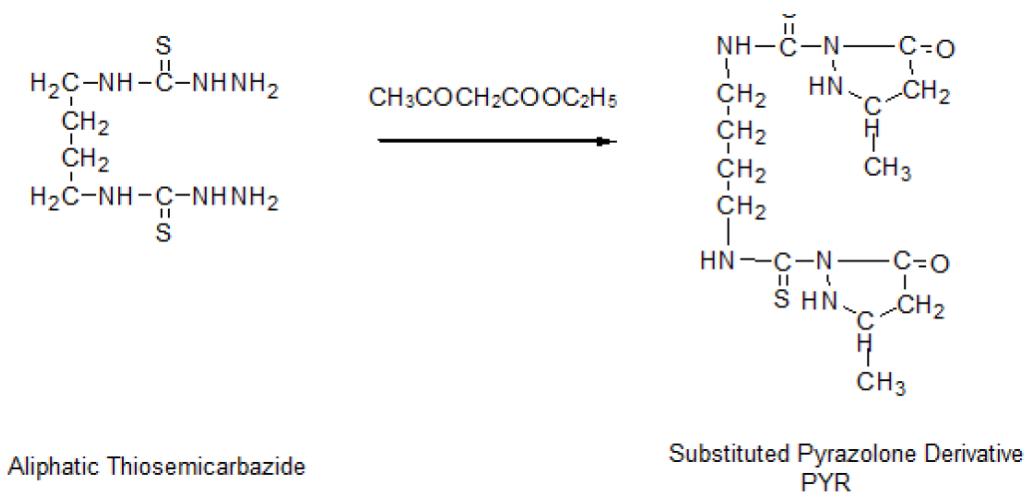

Scheme 2. Preparation of substituted pyrazolone derivative.

The concentration range employed was $3 \mathrm{ppm}$ to $11 \mathrm{ppm}$ by weight of PYR. Rectangular MS (composition: $0.09 \% \mathrm{P}, 0.38 \% \mathrm{Si}, 0.01 \% \mathrm{Al}, 0.05 \% \mathrm{Mn}, 0.21 \%$ $\mathrm{C}, 0.05 \% \mathrm{~S}$ and the reminder Fe) strips of the working surface area $3.5 \times 1.5 \mathrm{~cm}^{2}$ were used for weight loss studies and for electrochemical measurement were used MS rods of area $1 \mathrm{~cm}^{2}$ isolated with Teflon tape. $0.5 \mathrm{M} \mathrm{H}_{2} \mathrm{SO}_{4}$ solution was prepared by the dilution of analytical grade $\mathrm{H}_{2} \mathrm{SO}_{4}$ with double distilled water. The experiments were performed in $0.5 \mathrm{M} \mathrm{H}_{2} \mathrm{SO}_{4}$ without and with the presence of the inhibitor following the ASTM Standard procedure [25]. 


\section{Methods used for corrosion study \\ Weight loss studies}

Weight loss measurements were carried out by weighing the MS plates in triplicate before and after complete immersion in $100 \mathrm{~mL}$ of acid solution for 3 hours in the absence and presence of inhibitors of various concentrations. From the initial and final weight of the plate, the weight loss was calculated from which the degree of coverage $(\theta)$, inhibition efficiency $\left(\eta_{\mathrm{W}} \%\right)$, corrosion rate were calculated. The same procedure was carried out at different elevated temperatures $(313 \mathrm{~K}, 323 \mathrm{~K}, 333 \mathrm{~K}$ and $343 \mathrm{~K})$ using a thermostat to study the influence of temperature on the inhibitive effect of PYR.

\section{Electrochemical methods}

Electrochemical Impedance Spectroscopy (EIS) and potentiodynamic polarization were conducted in an electrochemical measurement unit (COMPACT STAT 10V; 30 Ma, IVIUM Model Parstat 2723, Advanced electrochemical system) to study the electrochemical behaviour of corrosion inhibition of PYR. The EIS measurements were made over a frequency range of $10 \mathrm{KHz}$ to $0.01 \mathrm{MHz}$ with signal amplitude of $25 \mathrm{mV}$. The Tafel polarization measurements were made after EIS for a potential range of $-100 \mathrm{mV}$ to $+100 \mathrm{mV}$ with respect to open circuit potential, at a scan rate of $1.66 \mathrm{mV} / \mathrm{sec}$. The $\mathrm{I}_{\text {corr }}$, $\mathrm{E}_{\mathrm{corr}}, \mathrm{R}_{\mathrm{ct}} \mathrm{C}_{\mathrm{dl}}$ and the Tafel slopes values were obtained from the data using the corresponding "Corr view" and "Z view" Software from which the corresponding inhibition efficiency $\eta_{\mathrm{P}} \%$ and $\eta_{\text {Rct }} \%$ were calculated electrochemically.

\section{Surface morphology}

The surface morphology of the exposed metal was studied using a Scanning Electron Microscope (SEM) in the absence and presence of the PYR. The SEM instrument used for analysis was JEOL made JSM 6390 model. The MS plates were immersed in a blank $0.5 \mathrm{M} \mathrm{H}_{2} \mathrm{SO}_{4}$ as well as in $11 \mathrm{ppm}$ inhibited acid solution for 3 hours. Then, the plates were removed, rinsed with distilled water and air dried and the surface morphology was studied.

\section{Quantum chemical studies}

Theoretical calculations for the $\eta \%$ of PYR in acid media were carried out using MOPAC Software. The quantum chemical parameters were computed for two different Hamiltonians, namely, Parametric Method 6 (PM6) and Parametric Method 7 (PM7). The optimized molecular structures and HOMO surfaces were visualized using chemcraft. Some electronic properties such as Energy of the Highest Occupied Molecular Orbital $\left(\mathrm{E}_{\mathrm{HOMO}}\right)$, Energy of the Lowest Unoccupied Molecular Orbital $\left(\mathrm{E}_{\mathrm{LUMO}}\right)$, Energy Gap $(\Delta \mathrm{E})$ between LUMO and HOMO, ionization potential, hardness and softness and electronegativity on the backbone of the atoms for PYR molecules were determined. 


\section{Results and discussion}

Weight loss studies

Effect of concentration of the inhibitor on inhibition efficiency

Fig. 1 gives the variation of inhibition efficiency with inhibitor concentration of mild steel in $0.5 \mathrm{M} \mathrm{H}_{2} \mathrm{SO}_{4}$ solution containing PYR at room temperature. It has been observed that there is a decrease in the loss in weight of MS plates with increasing the concentration of the inhibitor. This behaviour can be attributed to the increase in the number of adsorbed PYR molecules on MS surface via the lone pair of electrons on the hetero atoms $(\mathrm{O}, \mathrm{N} \& \mathrm{~S})$, blocking the active sites of acid attack and thereby protecting the metal from corrosion [26]. Thus it has been concluded that the corrosion inhibition of these compounds is due to the presence of heteroatoms $(\mathrm{O}, \mathrm{N}, \mathrm{S})$. A maximum efficiency of $91.17 \%$ was obtained at 11 ppm for $3 \mathrm{~h}$ immersion period.

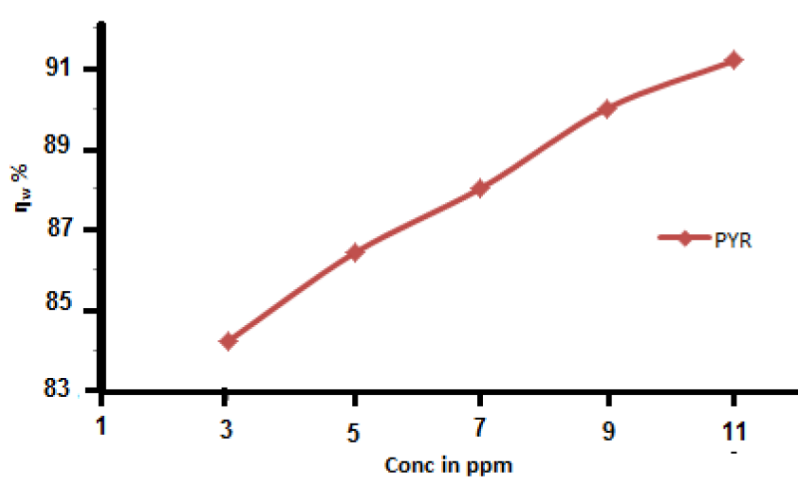

Figure 1. Effect of concentration on the $\eta_{\mathrm{w}}(\%)$ of PYR in $0.5 \mathrm{M} \mathrm{H}_{2} \mathrm{SO}_{4}$ from weight loss measurements at room temperature.

\section{Effect of temperature}

The effect of temperature on the corrosion behaviour of mild steel in acid medium in the presence of various concentrations of PYR is investigated by weight loss trends in the temperature range $303-343 \mathrm{~K}$ and the results are depicted in Fig. 2. As stays evident from the figure, the $\eta_{w} \%$ of PYR is inversely proportional to the temperature. This may be explained as follows: adsorption and desorption of the inhibitor molecule continuously occur at the metal surface and the equilibrium exists between these two processes at a particular temperature. With the increase of temperature, this equilibrium is shifted, leading to higher desorption rate than adsorption until equilibrium is again established at different value. This explains the low inhibition efficiency at higher temperature [27]. Thus, increase in temperature decreases the inhibition process and the highest $\eta_{\mathrm{w}} \%$ obtained is reached at $303 \mathrm{~K}$ for $11 \mathrm{ppm}$ which is to be $91.17 \%$ in $0.5 \mathrm{M} \mathrm{H}_{2} \mathrm{SO}_{4}$ medium.

\section{Adsorption isotherms}

The interaction between the PYR and the MS surface can be described by the adsorption isotherms which help in determining the mechanism of the organo electrochemical reaction [28]. The most frequently used isotherms are 
Langmuir, Frumkin, Temkin, Flory-Huggins, Freundlich, Dhar-Flory-Huggin, El-Awady, Bockris-Swinkels.

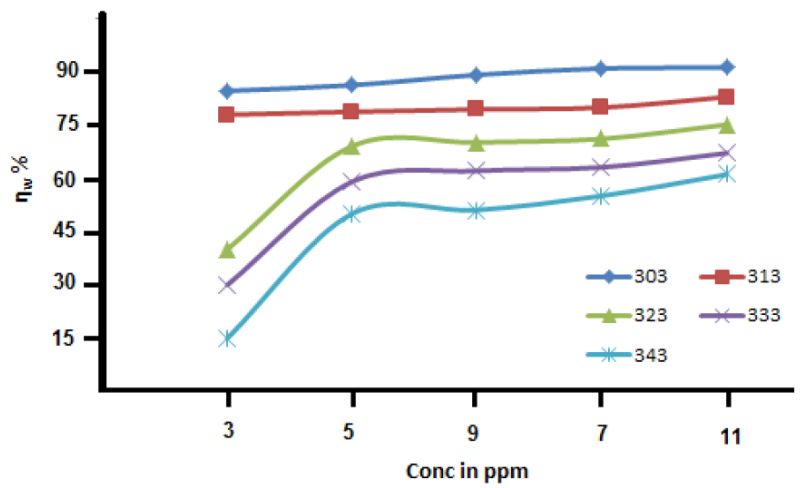

Figure 2. Effect of temperature on the $\eta_{\mathrm{w}} \%$ of PYR in $0.5 \mathrm{M} \mathrm{H}_{2} \mathrm{SO}_{4}$ from weight loss measurements.

In this study, Langmuir and Temkin isotherms were found to be suitable for the experimental findings. Langmuir adsorption equation relates the degree of the surface coverage to the concentration of the inhibitor according to equation (1)

$$
\log \left(\frac{c}{\theta}\right)=\log K+\log C
$$

Temkin isotherm is formulated as in equation (2)

$$
e(-2 a \theta)=k C
$$

where $\mathrm{C}$ is the inhibitor concentration, $k$ the adsorption equilibrium constant and $\theta$ is the surface coverage calculated from weight loss measurements for various concentrations at different temperature (Fig. $3 \mathrm{a}$ and $3 \mathrm{~b}$ ). The values of $\mathrm{R}^{2}$ were very close to unity indicating strong adherence of adsorption obeying the Langmuir and Temkin adsorption isotherms. The fit of the experimental data to these isotherms provides evidence for the role of adsorption in the observed inhibitive effect of PYR.

\section{Kinetic parameters}

The kinetic parameter of the system under consideration was evaluated from weight loss measurements at different temperatures. Activation energy (Ea) of corrosion reaction was calculated from the Arrhenius equation

$$
\log \text { corrosion rate }=-\left(\frac{E a}{2.303 \pi T}\right)+A
$$

The plot of log corrosion rate against 1/T gave straight lines from which Ea was calculated and tabulated in Table 1. From the table it is apparent that the activation energy $\left(\mathrm{E}_{\mathrm{a}}\right)$ of $\mathrm{MS}$ in $0.5 \mathrm{M} \mathrm{H}_{2} \mathrm{SO}_{4}$ is only $12.01 \mathrm{~kJ} / \mathrm{mol}$, but in the presence of PYR molecules, higher activation energies are observed. The increase in Ea is proportional to the inhibitor concentration. It is also indicated that the whole process is controlled by surface reaction as the energy of 
activation for the corrosion process is over $20 \mathrm{~kJ} / \mathrm{mol}$ [29]. This means that the adsorption of PYR on MS surface leads to the formation of a barrier layer that retards the metal activity in the electrochemical reactions of corrosion. Szauer and Brand explained that the increase in activation energy can be attributed to an appreciable decrease in the adsorption of the inhibitor on the MS with increase in the temperature and the corresponding increase in corrosion rate noted is due to the fact that greater area of metal is exposed to the acid media.

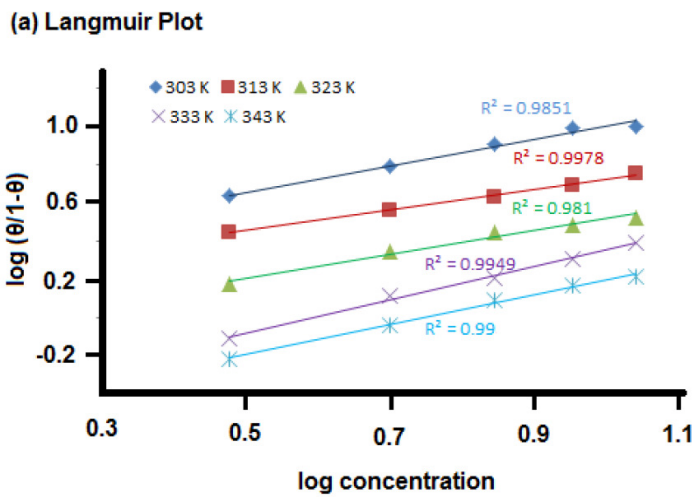

(b) Tempkin Plot

Figure 3. Langmuir (a) and Temkin (b) plots of PYR at various temperatures in $0.5 \mathrm{M} \mathrm{H}_{2} \mathrm{SO}_{4}$.

Table 1. Kinetic and thermodynamic parameters of mild steel in presence of PYR in $0.5 \mathrm{M} \mathrm{H}_{2} \mathrm{SO}_{4}$ at different temperatures.

\begin{tabular}{|c|c|c|c|c|c|c|c|c|}
\hline \multirow{2}{*}{$\begin{array}{c}\text { Conc } \\
(\mathbf{p p m})\end{array}$} & \multirow{2}{*}{$\begin{array}{c}\mathbf{E a} \\
(\mathbf{k J} / \mathbf{m o l})\end{array}$} & \multicolumn{3}{|c|}{$-\Delta \mathbf{G}^{\circ}{ }_{\text {ads }}(\mathbf{k J} / \mathbf{m o l})$} & \multicolumn{2}{c|}{$\begin{array}{c}\Delta \mathbf{H}^{\circ}{ }_{\text {ads }} \\
(\mathbf{k J J} / \mathbf{m o l})\end{array}$} & $\begin{array}{c}\Delta \mathbf{S}_{\text {ads }}^{\circ} \\
(\mathbf{J m o l} / \mathbf{K})\end{array}$ \\
\hline Blank & 12.01 & - & - & - & - & - & - & - \\
\hline 3 & 74.6 & -12 & -11 & -10 & -10 & -10 & -22 & -34 \\
\hline 5 & 76.9 & -11 & -10 & -9 & -8 & -8 & -30 & -63 \\
\hline 7 & 82.7 & -11 & -9 & -8 & -7 & -7 & -35 & -80 \\
\hline 9 & 93.9 & -9 & -8 & -7 & -7 & -6 & -26 & -57 \\
\hline 11 & 99.4 & -9 & -7 & -6 & -6 & -6 & -34 & -81 \\
\hline
\end{tabular}

\section{Thermodynamic parameters}

Thermodynamic parameters such as $\Delta \mathrm{G}^{\circ}$ ads, $\Delta \mathrm{H}^{\circ}$ ads and $\Delta \mathrm{S}^{\circ}$ ads were calculated from the temperature study results. The Gibbs free energy of adsorption $\Delta \mathrm{G}^{\circ}$ ads at different temperature was derived from the Langmuir plot using the relationship [30]

$$
\begin{aligned}
& \log \text { corrosion rate }=\log \left(\frac{\theta}{1-\theta}\right)-\log B \\
& \log B=-1.74-\Delta G^{\circ} / 2.303 R T
\end{aligned}
$$


The enthalpy of adsorption $\Delta \mathrm{H}^{\circ}$ ads and entropy of adsorption $\Delta \mathrm{S}^{\circ}$ ads were obtained from the slope and intercept of the plot of $\Delta \mathrm{G}^{\circ}$ ads against $\mathrm{T}$ according to the basic thermodynamic equation:

$$
\Delta G^{\circ}=\Delta H^{\circ}-T \Delta S^{\circ}
$$

and the values are tabulated in Table 1.

Generally, the values of $\Delta \mathrm{G}^{\circ}$ ads up to $-20 \mathrm{~kJ} / \mathrm{mol}$ are consistent with electrostatic interaction between the charged molecules and the charged metal surface (physical adsorption), while those more negative than $-40 \mathrm{~kJ} / \mathrm{mol}$ involve charge sharing or transfer from the inhibitor molecule to the metal surface (chemisorption). The calculated $\Delta \mathrm{G}^{\circ}$ ads values for PYR in $0.5 \mathrm{M} \mathrm{H}_{2} \mathrm{SO}_{4}$ are less than $-20 \mathrm{~kJ} / \mathrm{mol}$, indicating that PYR is physically adsorbed on the metal surface. The negative value of $\Delta \mathrm{G}^{\circ}$ abs shows a strong interaction of PYR molecules and spontaneous adsorption on the MS surface.

The negative sign of $\Delta \mathrm{H}^{\mathrm{o}}$ ads indicates that the spontaneous adsorption process is exothermic in nature. Generally, an exothermic adsorption process signifies either physisorption or chemisorption, while an endothermic process is attributed to chemisorption [31]. Typically, the enthalpy of physisorption is lower than - 41 $\mathrm{kJ} / \mathrm{mol}$, while the enthalpy of chemisorption approaches $100 \mathrm{~kJ} / \mathrm{mol}$. In the present study, the absolute value of enthalpy is in the range -20 to $-35 \mathrm{~kJ} / \mathrm{mol}$ suggesting physical adsorption.

The $\Delta \mathrm{S}^{\mathrm{o}}$ ads values in the presence of inhibitor are large and negative meaning a decrease in disordering on going from reactants to the metal adsorbed species.

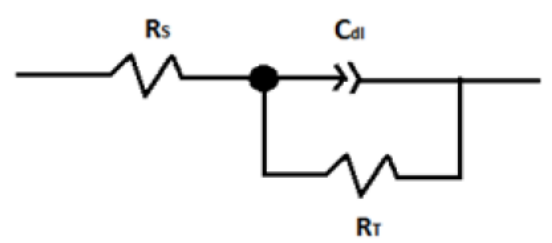

Figure 4. Equivalent circuit diagram for modeling the metal /solution interface without and with PYR.

\section{Electrochemical studies}

\section{Electrochemical impedance spectroscopy studies}

To determine the impedance parameters of PYR in these solutions, the measured impedance data were analyzed based on the equivalent circuit given in Fig. 4. The circuit consists of the double layer capacitance $\left(\mathrm{C}_{\mathrm{dl}}\right)$ in parallel to the charge transfer resistance $\left(\mathrm{R}_{\mathrm{ct}}\right)$. To obtain $\mathrm{C}_{\mathrm{dl}}$, the frequency $\left(f_{\text {max }}\right)$ at which the imaginary component of the impedance is maximal was found and used in equation (7):

$$
C d l=\left(\frac{1}{2 \pi}\right) f \max R c t
$$




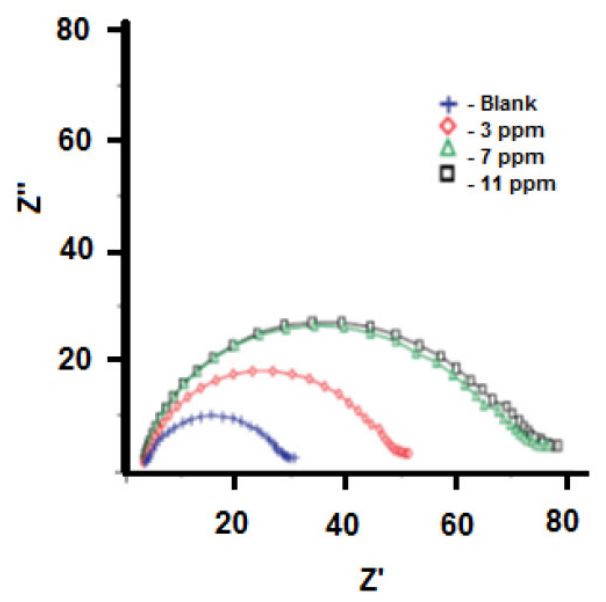

Figure 5. Impedance curves for the corrosion of mild steel with and without PYR in 0.5 $\mathrm{M} \mathrm{H}_{2} \mathrm{SO}_{4}$.

Table 2. Electrochemical parameters for the corrosion of mild steel with and without PYR in $0.5 \mathrm{M} \mathrm{H}_{2} \mathrm{SO}_{4}$.

\begin{tabular}{|ccccccccc|}
\hline $\begin{array}{c}\text { Conc } \\
(\mathbf{p p m})\end{array}$ & \multicolumn{2}{c}{$\begin{array}{c}\text { Electrochemical } \\
\text { impedance studies }\end{array}$} & \multicolumn{5}{c|}{ Potentiodynamic polarization studies } \\
\cline { 2 - 9 } & $\begin{array}{c}\mathbf{R}_{\mathbf{c t}} \\
(\mathbf{o h m s})\end{array}$ & $\begin{array}{c}\mathbf{C}_{\mathrm{dl}} \\
(\mathbf{f a r a d s}) \\
\times \mathbf{1 0}^{-5}\end{array}$ & $\begin{array}{c}\boldsymbol{\eta}_{\mathbf{R c t}} \\
(\mathbf{\%})\end{array}$ & $\begin{array}{c}\mathbf{I}_{\text {corr }} \\
\left(\boldsymbol{\mu} \mathbf{A} / \mathbf{c m}^{2}\right)\end{array}$ & $\begin{array}{c}\mathbf{E}_{\text {corr }} \\
(\mathbf{m V} \text { vs. SCE })\end{array}$ & $\begin{array}{c}\mathbf{b c} \\
(\mathbf{m V} / \mathbf{d e c})\end{array}$ & $\mathbf{b a}$ & $\begin{array}{c}\boldsymbol{\eta}_{\mathbf{P}} \\
(\boldsymbol{\%})\end{array}$ \\
\hline Blank & 9.95 & 1.55 & - & 1682 & -470.8 & 99 & 37 & - \\
\hline 3 & 30.84 & 1.66 & 67.7 & 272 & -487.4 & 79 & 31 & 84 \\
\hline 7 & 34.8 & 1.48 & 71.4 & 114 & -492.4 & 65 & 41 & 93 \\
\hline 11 & 43.58 & 1.45 & 77.2 & 91 & -494.2 & 63 & 40 & 95 \\
\hline
\end{tabular}

The inhibition efficiency of PYR was evaluated by $R_{c t}, C_{d l}$ and maximum phase angle $\left(\theta_{\max }\right)$ of the impedance. The existence of semicircle in the Nyquist plot (Fig. 5) indicates that the corrosion of mild steel in presence of PYR is mainly controlled by a charge transfer process. The more densely packed the layer of the inhibitor, larger is the diameter of the semicircle in the Nyquist plot which results in higher $\mathrm{R}_{\mathrm{ct}}$ and lower $\mathrm{C}_{\mathrm{dl}}$ values. Almost there was a gradual increase in the diameter of each semicircle of the Nyquist plot with increase in the concentration from 3 to $11 \mathrm{ppm}$. Results of the present work (Table 2) showed that the values of $R_{c t}$ increase with increasing PYR concentration, while the $C_{d l}$ values tend to decrease. The double layer between the charged metal surface and the solution is considered as an electrical capacitor. The adsorption of PYR on the electrode surface decreases its electrical capacity which is attributed to the formation of a protective layer on the electrode surface. This indicates that the inhibitor does not alter the electro chemical reaction responsible for corrosion, but inhibits corrosion primarily through its adsorption on the metal surface [32]. The thickness of the protective layer increases with increase in the concentration of the inhibitor as more PYR molecule get electrostatically adsorbed on the metal surface resulting in a noticeable decrease in the $\mathrm{C}_{\mathrm{dl}}$. This trend is in accordance with the Helmholtz model given by equation (8): 


$$
C d l=\frac{\pi z^{3} A}{d}
$$

where $\mathrm{d}$ is the thickness of the protective layer, $\varepsilon$ the dielectric constant of the medium, $\varepsilon^{\circ}$ the vacuum permittivity and $A$ is the effective surface area of the electrode.

The $\mathrm{R}_{\mathrm{ct}}$ values were used to calculate the inhibition efficiency of PYR at different concentrations using equation (9)

$$
\eta \%=\left[\frac{\text { Ret-Ret }}{\text { Ret }}\right] * 100
$$

where $\mathrm{R}_{\text {ct }}^{\circ}$ and $\mathrm{R}_{\mathrm{ct}}$ are the charge transfer resistance for uninhibited and inhibited solutions, respectively. It is apparent that the inhibition efficiency increases with increasing the concentration of the inhibitor. The results obtained from impedance are comparable and runs parallel with those obtained from potentiodynamic polarization and weight loss measurements [33].

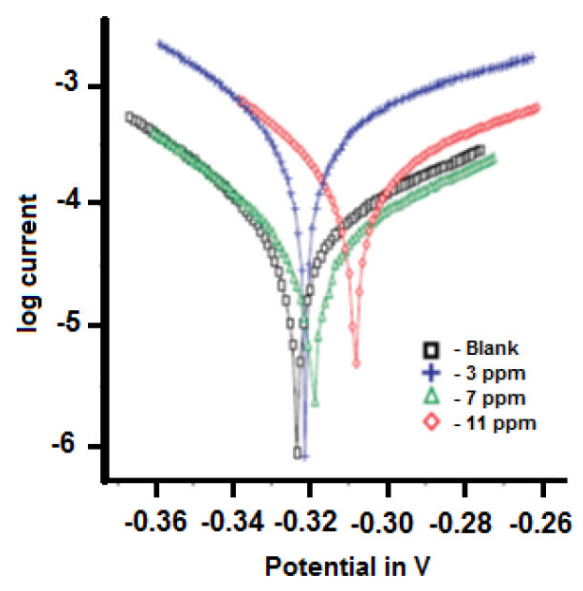

Figure 6. Potentiodynamic polarization curves for PYR in $0.5 \mathrm{M} \mathrm{H}_{2} \mathrm{SO}_{4}$.

\section{Potentiodynamic polarization studies}

Potentiodynamic polarization curves for MS in acid medium without and with different concentrations of the PYR are shown in Fig. 6. The corrosion kinetic parameters such as $\mathrm{E}_{\text {corr }}, \mathrm{I}_{\text {corr }}, \mathrm{b}_{\mathrm{c}}, \mathrm{b}_{\mathrm{a}}$ and $\eta_{\mathrm{P}} \%$ obtained from potentiodynamic polarization studies are listed in Table 2. The corrosion current density values decrease from $1685 \mu \mathrm{A} / \mathrm{cm}^{2}$ to $91 \mu \mathrm{A} / \mathrm{cm}^{2}$ for the addition of $11 \mathrm{ppm}$ of PYR resulting in $95 \%$ of inhibition efficiency. The increase in the inhibitor concentration decreases the $I_{\text {corr }}$ values. $E_{\text {corr }}$, ba and bc values do not change appreciably with the addition of the inhibitor, indicating that the inhibitor is not interfering with the anodic dissolution or cathodic hydrogen evolution reaction independently but acts as a mixed type of inhibitor. The above results signify that the inhibition mechanism occurs by simply blocking the available anodic and cathodic sites on the MS surface [34]. 


\section{Surface morphology}

Fig. 7a and 7b shows the SEM photograph of the steel surface in uninhibited and inhibited solution in $0.5 \mathrm{M} \mathrm{H}_{2} \mathrm{SO}_{4}$. The SEM photographs of the uninhibited MS sample showed large pit and crevices. These pits and crevices were developed during the corrosion of mild steel in acid medium. In Fig. $7 \mathrm{~b}$ the sample did not show any pits or crevices in highly acidic medium containing $11 \mathrm{ppm}$ of PYR for the same immersion period. A smoother surface is seen in the presence of PYR of 11ppm concentration in comparison with the blank [35]. Thus PYR has a stronger adherence towards the metal surface and it is resistant to corrosion in acidic medium. Moreover, this indicates the formation of a barrier coating of PYR molecule on the metal surface.
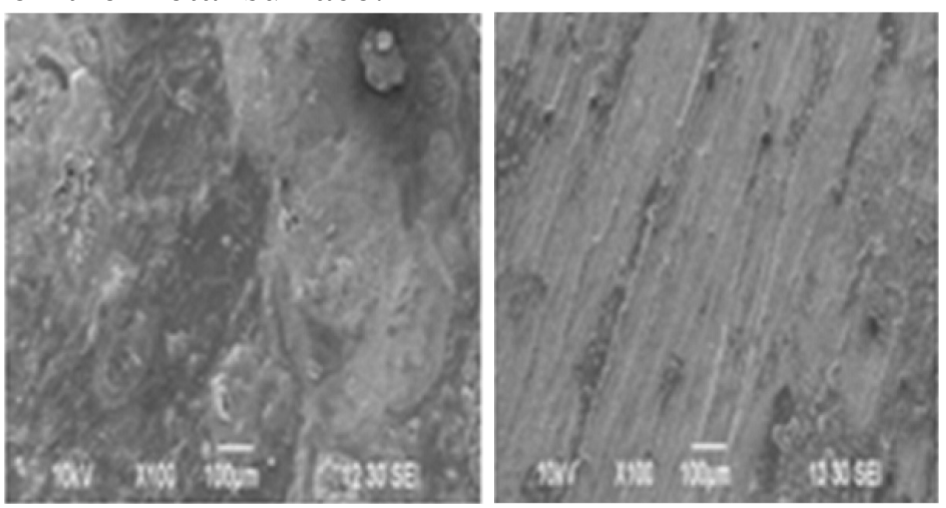

Figure 7. SEM images of MS in $0.5 \mathrm{M} \mathrm{H}_{2} \mathrm{SO}_{4}$ without (left) and with (right) PYR.

Table 3. Quantum chemical parameters for the corrosion inhibition of PYR in $0.5 \mathrm{M}$ $\mathrm{H}_{2} \mathrm{SO}_{4}$.

\begin{tabular}{|lcc|}
\hline Quantum chemical parameters & PM 7 & PM 6 \\
\hline Molecular formula & $\mathrm{C}_{14} \mathrm{H}_{20} \mathrm{~N}_{6} \mathrm{O}_{2} \mathrm{~S}_{2}$ & $\mathrm{C}_{14} \mathrm{H}_{20} \mathrm{~N}_{6} \mathrm{O}_{2} \mathrm{~S}_{2}$ \\
\hline $\mathrm{E}_{\mathrm{HOMO}}(\mathrm{eV})$ & -8.2 & -8.455 \\
\hline $\mathrm{E}_{\mathrm{LUMO}}(\mathrm{eV})$ & -0.60 & -0.42 \\
\hline$\Delta \mathrm{E}(\mathrm{eV})$ & 8.8 & 8.03 \\
\hline Molecular weight & 368.4 & 368.42 \\
\hline $\cos \mathrm{Ar}\left({ }^{\circ} \mathrm{A}^{2}\right)$ & 396.2 & 1205.009 \\
\hline $\left.\cos \mathrm{ol}^{\circ}{ }^{\circ} \mathrm{A}^{3}\right)$ & 425.1 & 3538 \\
\hline Ionisation potential $(\mathrm{V})$ & 8.24 & 6.11 \\
\hline Global hardness $(v)$ & 3.8 & 4.01 \\
\hline Absolute softness $(\sigma)$ & 0.26 & 0.24 \\
\hline Electronegativity $(\chi)$ & 4.4 & 4.43 \\
\hline
\end{tabular}

\section{Quantum chemical studies}

Quantum chemical study can be used to obtain information about the electronic interactions of the PYR molecules with the metal surface and pre-selection of new inhibitors on the basis of empirical knowledge [36]. The study reports the correlation between the observed inhibition efficiency of PYR used as corrosion inhibitor with its calculated quantum chemical parameters (Table 3).

Fig. $8 \mathrm{a}$ and $8 \mathrm{~b}$ shows the optimized geometry, HOMO density distribution and LUMO density distribution for PYR. The inhibitor layer has been related to the electronic structure of the molecule. The charge and orientation of the inhibitor molecule at the metal surface help in predicting the adsorption centre of the inhibitor molecule [37]. 


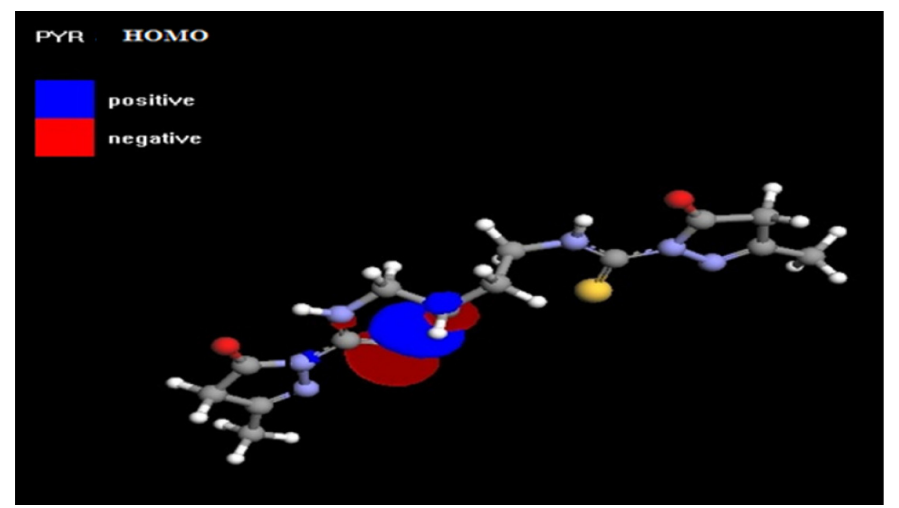

Figure 8a. Optimised structure for the HOMO of PYR.

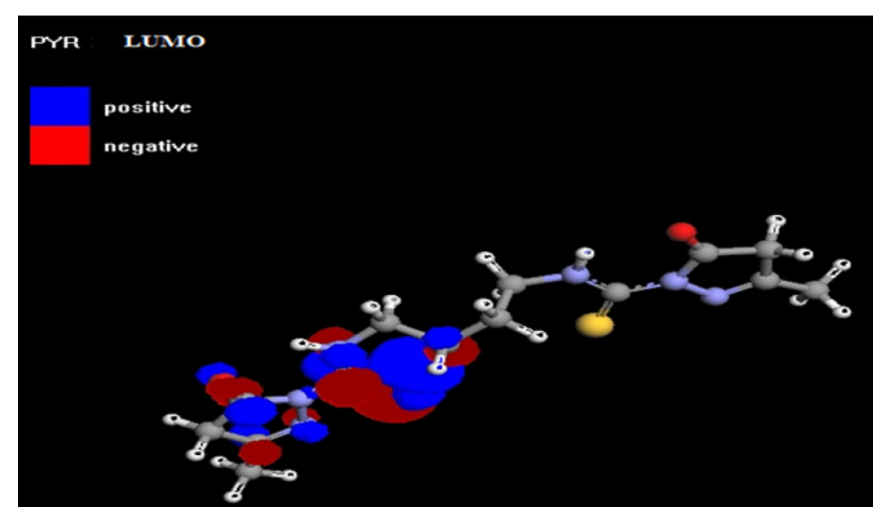

Figure 8b. 0ptimised structure for the LUMO of PYR.

Frontier molecular orbital energies $\left(E_{\text {HOMO }}\right.$ and $\left.E_{L U M O}\right)$

The frontier molecules orbital energies (i.e.), $\mathrm{E}_{\mathrm{HOMO}}$ and $\mathrm{E}_{\mathrm{LUMO}}$, are significant parameters for the prediction of the reactivity of a chemical species. $\mathrm{E}_{\mathrm{HOMO}}$ is associated with the electron donating ability of a molecule as the $\mathrm{E}_{\mathrm{LUMO}}$ indicates the ability of the molecule to accept electrons [38 - 40]. The increasing values of $\mathrm{E}_{\mathrm{HOMO}}$ facilitate the adsorption of the PYR on MS surface as the $\mathrm{E}_{\mathrm{LUMO}}$ decreases in a similar order. Smaller the $\Delta \mathrm{E}$ value greater is the inhibitive action. Here the lower value of $\Delta \mathrm{E}$ also agrees with the excellent inhibition efficiency of PYR on MS surface in $0.5 \mathrm{M} \mathrm{H}_{2} \mathrm{SO}_{4}$.

\section{Global hardness and absolute softness}

Literature reveals that the larger energy gap indicates the low reactivity as the energy gap is related to the softness and hardness of a molecule. A soft molecule is more reactive than a hard molecule. The low value of absolute softness $(\sigma)$ for PYR suggests it to be a strong inhibitor for MS surface [41].

\section{Electronegativity}

Electronegativity $(\chi)$ is a chemical property that describes the ability of a molecule to attract electrons towards itself in a covalent bond. The result deduced indicates that the electron flow will happen from the molecule with the low electronegativity towards that of a higher value. The best inhibitor of PYR is attributed to its low electronegativity. 
The inhibitor efficiency increases as the molecular weight, molecular volume and molecular area of the molecules increase, due to the increase of the contact area between the molecule and the surface [42-46]. Small ionization energy indicates high reactivity of the atoms and molecules. Hereby, the theoretical values also justify the experimental results.

\section{Mechanism of inhibition}

Corrosion protection of mild steel in $0.5 \mathrm{M} \mathrm{H}_{2} \mathrm{SO}_{4}$ solution by PYR can be explained on the basis of molecular adsorption. Electrochemical and SEM analysis clearly reveals the formation of a protective barrier of PYR molecules which are strongly adsorbed on the mild steel surface. Electro chemical results showed that PYR protects MS from corrosion by controlling both the anodic and cathodic reactions. The adsorption on the anodic sites occurs through the lone pair of electrons on the hetero atoms thereby decreasing the anodic dissolution of metal by interacting with the empty $d$ orbitals of the metal. In acidic medium, the PYR molecules exist as protonated species. Iron in acid medium is negatively charged and the existence of protonated species acts as anchoring site which can adsorb on the cathodic sites on the metal thereby reducing the hydrogen evolution [47-50]. Moreover, from the HOMO structure, the electro donating ability of the compound is localized on the nitrogen atoms which can be protonated in acid medium. These sites are the preferred sites of absorption on the metal surface. Thus theoretical studies also confirm the experimental results.

\section{Conclusion}

The following conclusions are derived from the present work on PYR as corrosion inhibitor for mild steel in $0.5 \mathrm{M} \mathrm{H}_{2} \mathrm{SO}_{4}$ over certain range of concentration at various temperatures by non- electro chemical, electro chemical and quantum chemical studies .

- The inhibition efficiency increases with increase in the concentration of these inhibitors but decreases with rise in temperature. The inhibitive action of PYR is due to the presence of heteroatoms $(\mathrm{O}, \mathrm{N}, \mathrm{S})$.

- The adsorption of PYR on the metal surface follows Langmuir and Temkin adsorption isotherms. The phenomenon of physisorption is proposed from the calculated thermodynamic parameters although the values are slightly intermediate.

- The activation energy $\left(\mathrm{E}_{\mathrm{a}}\right)$ is higher for inhibited acids than for the uninhibited acids confirming that the studied pyrazolone derivative is a good inhibitor.

- The Tafel constants obtained from potentiodynamic polarization curves indicate that PYR is of mixed type inhibitor.

- The SEM results confirm the presence of a protective surface layer over the MS surface.

- Theoretical findings reveal a good prediction of the inhibition efficiency which co-relates with the experimental results.

Thus, the conclusion from all the carried out studies, i.e., weight loss measurement, thermodynamic value, activation energy, electro chemical 
parameters, SEM and quantum chemical investigation, clearly affirm the physical adsorption of PYR on the MS surface. The comprehensive discourse presented concludes that the pyrazolone derivatives fulfil the basic requirements for consideration as an efficient corrosion inhibitor.

\section{References}

1. Sykes JM. Br Corros J. 1990;25:175.

2. Nuynth N, Bottle SE, Notoya T, et al. Corros Sci. 2002;44:2583.

3. Ozcan M, Dehri I, Erbil M. Appl Surf Sci. 2004;236:155.

4. Wong HI, Fan I, Zheng J. Mater Chem Phys. 2004;77:655.

5. Larabi L, Harek Y, Traisnel M, et al. J Appl Electrochem. 2004;34:833.

6. Khaled KF. Appl Surf Sci. 2004;230:307.

7. Herek Y, Larabi L. Kem Ind. 2004;53:55.

8. Babic K, Samardzija, Khaled KF, et al. Appl Surf Sci. 2005;240:327.

9. Frignami A, Monticelli C, Brunoro G, et al. Br Corros J. 1987;22:103.

10. Chetouani A, Hammouti B, Aounti A, et al. Prog Org Coat. 2002;45:373.

11. Benerjee G, Malhotra SN. Corros. 1992;48:10.

12. El-Sayed A. J Appl Electrochem. 1997;27:193.

13. Rengamani S, Muralidharan S, Kulandainathan MA, et al. J Appl Electrochem. 1994;24:355.

14. Agarwal R., Namboodhiri TKG. J Appl Electrochem. 1992;22:383.

15. Fiaud C, Harch A, Mallouh D, et al. Corros Sci. 1993;35:1437.

16. Khamis E. Corros. 1990;46:476.

17. Stupnisek-Lisac E, Podbrscek S. J Appl Electrochem. 1994;24:779.

18. Granese SL. Corros. 1988;44:322.

19. Growcock FB. Corros. 1989;45:1003.

20. Lukovis I, Shaban A, Kalman E. Corros. 1997;53:915.

21. Lukovis I, Shaban A, Kalman E. Russ J Electrochem. 2003:177.

22. Bentiss F, Lagrenee M, Vezin H, et al Corros Sci. 2003;45:371.

23. Abdel Hameed AS, Al-Shafy HI, Abul Magd AS, et al. J Mater Environ Sci. 2012;32:294-305.

24. Herrag L, Chetouani A, Elkadiri S, et al. Port Electrochim Acta. 2008;26:211.

25. ASTM - G - 12, "Wear and Erosion: Metal Corrosion", Annual book of ASTM standard, ASTm, West Conshohocken, PA. 1996:30-37.

26. Al-Mutairi AA, El-Baih FEM, Al-Hazimi HM. J Saudi Chem Soc. 2010;14:287.

27. Shivakumar SS, Mohana KN. Int J Electrochem Sci. 2012;7:1620.

28. Damaski BB, Petri AO, Batraktov B. Adsorption of organic compounds on electrodes. new York:Plenum Press; 1972.

29. Eddy NO, Ebenso EE, Ibok UJ. J Appl Electrochem. 2010;40:445.

30. Nalini D, Rajalakshmi R, Subhashini S. e-J Chem. 2011;8:671.

31. Firdhouse MJ, Nalini D. J Chem. 2013:9.

32. Loto RT, Loto CA, Popoola API, et al. Int J Phy Sci. 2012;7:213. 
33. Alaoui LM, Hammouti B, Bellaouchou A, et al. Der Pharma Chemica. 2011;3:353.

34. Bhandari H, Srivastav R, Choudhary V, et al. Thin Solid Films. 2010;519:1031.

35. Ebenso EE, Obot IB. Int J Electrochem Sci. 2010;5:2012.

36. Eddy NO, Ebenso EE. Int J Electrochem Sci. 2010;5:731.

37. Praveen BM, Venkatesha TV. Int J Electrochem Sci. 2009;4:258.

38. Noor EA, Al-Moubaraki AH. Int J Electrochem Sci. 2008;3:806.

39. Eddy NO, Odoemelam SA, Mbaba AJ. Africa J Pure Appl Chem. 2008;2:132.

40. Laarej K, Bouachrine M, Radi S, et al. e-J Chem. 2010;7:419.

41. Obi-Egbed NO, Obot IB, M.I. El-Khaiary MI, et al. Int J Electrochem Sci. 2011;6:5649.

42. Tripathi R, Chaturvedi A, Upadhayay RK. Res J Chem Sci. 2012;2:18.

43. Khaled KF. Mat Chem Phys. 2010;124:760.

44. Singh AK, Quarishi MA. Corros Sci. 2010;52:152.

45. Khaled KF. Corros Sci. 2010;52:3225.

46. Bentiss F, Labrini M, Vezin H, et al. Corros Sci. 2009;51:2165.

47. Mansfeild F. Corros. 1981;37:3001.

48. Murakawa T, Hackerman N. Corros Sci. 1964;4:387.

49. Donalhue FM, Nobe K. J Electrochem Soc. 1965;112:886.

50. Larabi L, Benali O, Mekelleche SM, et al. Appl Surf Sci. 2006;253:1371. 